\title{
Senam Nifas Memengaruhi Proses Involutio Uteri
}

\author{
Hastuti Usman ${ }^{1 *}$, Artika Dewie ${ }^{1}$, Muthmainnah Ahsan ${ }^{2}$ \\ ${ }^{1}$ Jurusan Kebidanan Poltekkes Kemenkes Palu \\ ${ }^{2}$ Puskesmas Nambo Kabupaten Banggai \\ *Email korespondensi: bid.hastuti@gmail.com
}

\section{Article Info}

\section{ABSTRACT}

Article history:

Submitted: 2019-07-22

Accepted: 2019-12-21

Published: 2019-12-30

Keywords:

Postpartum

Gymnastics; Uteric Involution.

Postpartum mothers are afraid to do many movements. If mothers do early ambulation, it can facilitate the process of uterine involution. This research is aim to clear out the effect of puerperal gymnastic on the uterine involution process to postpartum mothers. It uses a quasiexperiment design and Pretest and posttest control group design. The sampling technique uses an accidental sampling technique. The instrument in this study is the observation sheet, leaflet, and gymnastics guide. Statistical test using the Mann Whitney test. Before performing puerperal gymnastic, the average of the Fundal Height (Tinggi Fundus Uteri) of the intervention group was $10.9 \mathrm{~cm}$, and the average of Fundal Height of the control group was $10.9 \mathrm{~cm}$. The statistical test obtained $p$-value $=0.457$, which means there is no difference in the average the Fundal Height between the intervention group and the control group. Whereas after childbirth exercise, the average of Fundal Height of the intervention group was $0.9 \mathrm{~cm}$, and the average of Fundal Height of the control group was $7.3 \mathrm{~cm}$. Statistical test obtained $p$-value $<0.001$. To sum up, there is an effect of puerperal exercise on uterine involution speed. Suggestions for Puskesmas Kampung Baru, especially the midwives, are to provide postpartum gymnastics services for postpartum mothers to accelerate uterine involution.

\section{ABSTRAK}

Kata Kunci:

Senam Nifas; Involutio Uteri.
Para ibu pasca melahirkan takut melakukan banyak gerakan, apabila ibu bersalin melakukan ambulasi dini, Itu bisa memperlancar terjadinya proses involusi uteri. Tujuan peneilitian ini adalah untuk mengetahui pengaruh senam nifas terhadap proses involutio uteri pada ibu pasca salin. Desain penelitian dengan racangan quasy experiment pretest posttest control group design. Teknik pengambilan sampel menggunakan teknik accidental sampling, Instrument dalam penelitian ini lembar observasi, leaflet dan panduan senam. Uji statistik menggunakan uji Mann Whitney. Sebelum dilakukan tindakan senam nifas diperoleh rata-rata TFU kelompok intervensi adalah $10,9 \mathrm{~cm}$ dan rata-rata TFU kelompok kontrol adalah $10,9 \mathrm{~cm}$. Hasil uji statistik diperoleh nilai $p=0,457$ yang berarti tidak ada perbedaan rata-rata TFU antara kelompok intervensi dan kelompok kontrol. Sesudah dilakukan senam nifas rata-rata TFU kelompok intervensi adalah $0,9 \mathrm{~cm}$ dan rata-rata TFU kelompok kontrol adalah $7,3 \mathrm{~cm}$. Hasil uji statistik diperoleh nilai $p<0,001$. Kesimpulan terdapat pengaruh senam nifas terhadap kecepatan involutio uteri. Saran bagi Puskesmas Kampung Baru khusunya bidan disarankan untuk memberikan pelayanan senam nifas bagi ibu post partum guna mempercepat involutio uteri. 


\section{PENDAHULUAN}

Masa nifas (puerperium) adalah masa post partum atau masa sejak bayi dilahirkan dan plasenta keluar lepas dari rahim sampai 6 minggu berikutnya disertai pulihnya kembali organ-organ yang berkaitan dengan kandungan yang mengalami perubahan seperti perlukaan dan lain sebagainya yang berkaitan saat melahirkan. ${ }^{1}$ Pada masa ini umumnya ibu takut melakukan banyak gerakan oleh karena merasa khawatir akan gerakan-gerakan yang dilakukannya dapat menimbulkan dampak yang tidak diinginkan, sebaliknya apabila ibu melakukan aktivitas atau ambulasi dini maka hal tersebut bisa memperlancar terjadinya proses involutio uteri. Ketidaklancaran proses involusi dapat berakibat buruk pada ibu nifas seperti terjadi perdarahan yang bersifat lanjut. ${ }^{2}$ Salah satu tujuan perawatan nifas adalah menjaga kesehatan ibu dan bayi baik secara fisik maupun psikologis. Perawatan pasca persalinan diperlukan pada periode ini karena merupakan periode kritis untuk ibu dan bayi. ${ }^{3}$

Semua wanita akan sembuh dari persalinannya dengan waktu yang berbeda-beda, oleh sebab itu untuk mempercepat proses tersebut maka senam nifas sangat dianjurkan. Senam nifas adalah senam yang dilakukan ibu post partum setelah keadaan tubuhnya pulih kembali yang gerakannya sama dengan senam antenatal. Penting bagi ibu agar senam tersebut hendaknya dilakukan secara bertahap sistematis dan kontinu sejak hari pertama setelah melahirkan hingga hari ke sepuluh. ${ }^{2,4}$ Hasil penelitian menunjukkan bahwa ibu post partum yang melakukan senam nifas pemulihan fisiknya lebih cepat meningkat, mempunyai keadaan umum yang baik, sirkulasi yang lancar, proses laktasi yang baik serta involutio uteri yang semakin cepat. ${ }^{4}$

Data Survei Demografi Kesehatan Indonesia, Angka Kematian Ibu (AKI) tahun 2016 adalah 4.912 per 100.000 kelahiran hidup dan di tahun 2017 (Januari-Juni) sebanyak 1712 per 100.000 kelahiran hidup, ${ }^{5}$ AKI Sulawesi Tengah Tahun 2016 adalah 105 per 100.000 kelahiran hidup, dan pada tahun 2017 meningkat menjadi 141 per 100.000 kelahiran hidup. Penyebab terbanyak adalah lain-lain (Hepatitis B, Malaria, TBC) $54 \%$, perdarahan $18 \%$, hipertensi dalam kehamilan $16,9 \%$, gangguan peredaran darah dan jantung $5,6 \%$, sepsis $3,3 \%$, dan gangguan metabolik $2,2 \% .6,7$ AKI Kabupaten Banggai tahun 2017 terdapat 9 kasus kematian atau 134 per 100.000 kelahiran hidup dengan penyebab eklpamsi 4 kasus, anemia 2 kasus, perdarahan 1 kasus, pasca operasi 1 kasus, sepsis 1 kasus, terjadi peningkatan pada tahun 2018 yaitu 10 kasus atau 148 per 100.000 kelahiran hidup dengan penyebab terbanyak perdarahan yaitu 8 kasus, hipertensi dalam kehamilan 1 kasus dan gangguan metabolisme 1 kasus. ${ }^{8,9}$

Banyak faktor penyebab tidak dilakukannya senam nifas diantaranya ketidaktahuan tentang cara melakukan senam nifas, menikmati masa bahagia akan kelahiran anak, dan masih dalam istirahat untuk memulihkan tenaga yang telah dikeluarkan selama persalinan studi pendahuluan yang dilakukan di Puskesmas Kampung Baru Luwuk diperoleh data pada tahun 2017 jumlah ibu nifas adalah 706 ibu nifas pada tahun 2017 dan selama ini belum pernah dilakukan kelas senam nifas serta tidak pernah dilakukan penyuluhan tentang senam nifas. Tujuan penelitian adalah mengetahui pengaruh senam nifas terhadap perubahan involutio uteri pada ibu nifas di Puskesmas Kampung Baru. 


\section{METODE PENELITIAN}

Penelitian ini menggunakan jenis dan desain penelitian dengan racangan quasy experiment..$^{10}$ Populasi dalam penelitian ini adalah seluruh ibu post partum di Puskesmas Kampung Baru. Sampel adalah ibu post partum yang melahirkan normal yang berjumlah 30 responden dihitung menggunakan rumus sampel estimasi. Teknik Pengumpulan data primer yaitu responden dibagi menjadi dua kelompok, kelompok eksperiment dilakukan pemeriksaan involutio uteri kemudian responden dipandu untuk melakukan senam pada 2 jam post partum, selanjutnya dilakukan dengan melatih senam nifas setiap hari dengan kunjungan rumah selama enam hari. Pada hari ke tujuh dilakukan kembali pengukuran tinggi fundus dengan menggunakan lembar observasi. Pada kelompok kontrol sebelumnya dilakukan pemeriksaan involutio uteri, pada 2 jam post partum kemudian responden diberikan leaflet. Pada hari ke tujuh dilakukan kembali pengukuran involutio uteri dengan menggunakan lembar observasi. Penelitian dilakukan pada tanggal 01 Mei-01 Juni 2019 di Puskesmas Kampung baru dan kunjungan ke rumah responden. Uji statisik yang digunakan adalah uji Mann Whitney

\section{HASIL PENELITIAN}

Setelah data penelitian dianalisis maka diperoleh hasil sebagai berikut:

Tabel 1. Distribusi Frekuensi Responden berdasarkan Klasifikasi Kelompok Usia, Pendidikan, Pekerjaan, Paritas dan ASI Ekslusif.

\begin{tabular}{|c|c|c|c|c|c|}
\hline \multirow{3}{*}{ Karateristik } & \multirow{3}{*}{ Kategori } & \multicolumn{4}{|c|}{ Kelompok } \\
\hline & & \multicolumn{2}{|c|}{$\begin{array}{c}\text { Intervensi } \\
\text { (Senam Nifas) }\end{array}$} & \multicolumn{2}{|c|}{$\begin{array}{c}\text { Kontrol } \\
\text { (Pemberian Leaflet) }\end{array}$} \\
\hline & & n & $\%$ & $\mathbf{n}$ & $\%$ \\
\hline \multirow[t]{2}{*}{ Umur } & $20-30$ & 14 & 46,7 & 14 & 46,7 \\
\hline & $>35$ & 1 & 3,3 & 1 & 3,3 \\
\hline \multirow[t]{5}{*}{ Pendidikan } & SD & 0 & 0,0 & 1 & 3,3 \\
\hline & SMP & 0 & 0,0 & 1 & 3,3 \\
\hline & SMA & 11 & 36,7 & 8 & 26,7 \\
\hline & Perguruan & 4 & 13,3 & 5 & 16,7 \\
\hline & Tinggi & & & & \\
\hline \multirow[t]{4}{*}{ Pekerjaan } & IRT & 13 & 43,3 & 11 & 36,7 \\
\hline & Honor & 1 & 3,3 & 3 & 10,0 \\
\hline & Karyawan & 1 & 3,3 & 1 & 3,3 \\
\hline & Swasta & & 232 & & 020 \\
\hline \multirow{2}{*}{ Paritas } & $\begin{array}{l}\text { Primipara } \\
\text { Multipara }\end{array}$ & $\begin{array}{l}7 \\
7\end{array}$ & $\begin{array}{l}23,3 \\
23,3\end{array}$ & $\begin{array}{l}6 \\
8\end{array}$ & $\begin{array}{l}20,0 \\
267\end{array}$ \\
\hline & Grandemultipara & 1 & 3,3 & 1 & 3,3 \\
\hline \multirow[t]{2}{*}{ Asi Ekslusif } & Ya & 13 & 43,3 & 8 & 26,7 \\
\hline & Tidak & 2 & 6,7 & 6 & 20,0 \\
\hline
\end{tabular}

Tabel 1 menunjukan gambaran distribusi frekuensi responden berdasarkan kelompok umur, pendidikan,pekerjaan,paritas dan asi ekslusif. Sebagian besar responden memiliki umur berusia 20-30 tahun, memiliki pendidikan SMA, Memiliki pekerjaan IRT, lebih banyak primipara dan multipara dan yang memberikan ASI ekslusif. 
Tabel 2. Distribusi Frekuensi Sebelum dan Sesudah Dilakukan Tindakan pada Responden di Puskesmas Kampung Baru Kabupaten Banggai

\begin{tabular}{lcccccc}
\hline \multirow{2}{*}{ Senam } & \multicolumn{2}{c}{ Lambat } & \multicolumn{2}{c}{ Normal } & \multicolumn{2}{c}{ Cepat } \\
\cline { 2 - 7 } & $\mathbf{n}$ & $\%$ & $\mathbf{n}$ & $\%$ & $\mathbf{n}$ & $\%$ \\
\hline Sebelum & & & & & & \\
Intervensi & 15 & 50 & - & - & - & - \\
Kontrol & 15 & 50 & - & - & - & - \\
Sesudah & & & & & & \\
Intervensi & 0 & 0 & 2 & 6,6 & 13 & 43,4 \\
Kontrol & 5 & 16,6 & 9 & 30,0 & 3 & 3,4 \\
\hline
\end{tabular}

Berdasarkan tabel 2 sebelum dilakukan tindakan diketahui bahwa kelompok intervensi terdapat 15 responden (50\%) yang memiliki kategori kecepatan lambat dan kelompok kontrol terdapat 15 responden $(50 \%)$ yang memiliki kategori kecepatan lambat dan sesudah dilakukan tindakan dapat diketahui bahwa kelompok intervensi pada kategori normal sebanyak 2 responden $(6,6 \%)$ sedangkan kategori cepat sebanyak 13 responden $(43,4 \%)$. Kelompok kontrol pada kategori lambat 5 responden $(16,6 \%)$, kategori normal 9 responden $(30 \%)$ dan kategori cepat 1 responden $(3,4 \%)$.

Tabel 3 Hasil Analisis Sebelum dan Setelah Tindakan Senam Nifas terhadap Proses Involutio Uteri di Puskesmas Kampung Baru Kabupaten Banggai

\begin{tabular}{cccc}
\hline Kelompok & Jumlah & Rata-rata TFU & $\boldsymbol{P}$ Value \\
\hline $\begin{array}{c}\text { Sebelum } \\
\text { Intervensi }\end{array}$ & 15 & 10,9 & \\
$\quad$ Kontrol & 15 & 10,9 & 0,457 \\
$\begin{array}{c}\text { Setelah } \\
\text { Intervensi }\end{array}$ & 15 & 0,9 & $<0,001$ \\
$\quad$ Kontrol & 15 & 7,3 & \\
\hline
\end{tabular}

Sebelum dilakukan tindakan senam nifas diperoleh rata-rata TFU kelompok intervensi adalah $10,9 \mathrm{~cm}$ dan rata-rata TFU kelompok kontrol adalah $10,9 \mathrm{~cm}$ dengan hasil nilai $p=0,457$ artinya tidak ada perbedaan rata-rata TFU antara kelompok intervensi dan kelompok kontrol, sesudah dilakukan senam nifas ata-rata TFU kelompok intervensi adalah $0,9 \mathrm{~cm}$ dan rata-rata TFU kelompok kontrol adalah $7,3 \mathrm{~cm}$. Hasil uji statistik dengan uji Mann Whitney diperoleh $p$ value $<0,001$ berarti ada perbedaan rata-rata TFU antara kelompok intervensi dan kelompok kontrol. Hal ini menunjukan bahwa pada kelompok intervensi atau dilakukan senam nifas secara rutin sejak hari pertama sampai hari ke tujuh post partum memiliki pengaruh terhadap involutio uteri dibandingkan dengan kelompok kontrol yang tidak diberikan intervensi senam nifas hanya diberikan leaflet saja.

\section{PEMBAHASAN}

Proses involusi uterus bisa lebih cepat atau lebih lambat. Ada berbagai faktor yang dapat mempengaruhi involusi uteri salah satunya adalah mobilitas ibu. Mobilitas adalah kemampuan seseorang untuk berjalan naik dan kembali ke tempat tidur, kursi, dudukan toilet, dan sebagainya di samping kemampuan untuk memindahkan ekstremitas atas. Mobilisasi dini ibu nifas adalah bentuk kegiatan yang dilakukan segera dan sesegera mungkin setelah proses persalinan. Penting untuk proses penurunan fundus uterus dan mempercepat proses penyembuhan pada ibu postpartum sehingga mobilisasi dini sesuai untuk terapi non-farmakologis yang harus 
diintervensi pada ibu postpartum. Hal ini juga berguna dalam mengeluarkan lokia, mengurangi infeksi peurperium, mempercepat involusi uterus, memfasilitasi perangkat gastrointestinal dan urin, meningkatkan sirkulasi darah, sehingga mempercepat fungsi ASI dan membuang sisa metabolisme. Mobilisasi ibu nifas dapat dilakukan dengan olahraga awal atau senam nifas. ${ }^{11,12}$

Salah satu cara untuk menjaga kontraksi tetap baik sampai akhir persalinan adalah mobilisasi dan gerakan sederhana seperti senam nifas. Karena dengan proses nifas, otot-otot dalam rahim akan berkontraksi dan menarik, yang dapat menyebabkan pembuluh darah di rahim meregang sehingga perdarahan dapat dihindari. ${ }^{13}$

Manfaat senam nifas adalah membantu penyembuhan rahim, perut, dan otot pinggul yang mengalami trauma serta mempercepat kembalinya bagian-bagian tersebut ke bentuk normal, membantu menormalkan sendi-sendi yang menjadi longgar diakibatkan kehamilan dan persalinan, serta mencegah pelemahan dan peregangan lebih lanjut dan menghasilkan manfaat psikologis yaitu menambah kemampuan menghadapi stress dan bersantai sehingga mengurangi depresi pasca persalinan. ${ }^{1}$

Hal ini sejalan dengan hasil penelitian di Kabupaten Rembang Tahun 2016 yang menunjukan hasil ada pengaruh senam nifas terhadap proses involutio uteri. ${ }^{14}$ Penelitian membuktikan bahwa kecepatan involusi uterus pada ibu nifas yang melakukan senam nifas mayoritas berada pada kategori cepat sebanyak 16 orang $(76,19 \%)$, kecepatan involusi uterus pada ibu nifas yang tidak melakukan senam nifas mayoritas berada pada kategori tepat sebanyak 16 orang $(76,19 \%)$, dan terdapat pengaruh dari senam nifas terhadap kecepatan involusi uterus pada ibu nifas. ${ }^{15}$

Gerakan pada senam nifas dapat melatih dan mengencangkan otot perut sehingga secara tidak langsung dapat merangsang otot rahim agar berfungsi secara optimal dan tidak terjadi perdarahan post partum. Dengan demikian tujuan dilakukannya senam nifas bagi ibu nifas yaitu memperbaiki elastisitas otot yang telah mengalami peregangan, meningkatkan ketenangan, memperlancar sirkulasi darah, dan mengembalikan rahim pada posisi semula (involutio uteri). ${ }^{16}$

Dalam proses penelitian para responden sangat kooperatif dan mau mengikuti petunjuk yang diberikan, dengan dilakukannya senam nifas maka terjadi kontraksi otot-otot perut yang juga dapat membantu proses involutio uteri, begitupun sebaliknya jika ibu nifas yang tidak melakukan senam nifas maka proses involutio uteri akan berlangsung lambat.

\section{SIMPULAN DAN SARAN}

Terdapat pengaruh senam nifas terhadap kecepatan involitio uteri pada ibu post partum di Puskesmas Kampung Baru Kabupaten Banggai. Penelitian ini menyarankan bidan untuk memberikan pelayanan senam nifas dan diwajibkan bagi ibu post partum guna mempercepat Involutio uteri.

\section{UCAPAN TERIMA KASIH}

Peneliti menyampaikan terima kasih kepada Kepala Puskesmas Kampung Baru, bidan koordinator puskesmas Kampung Baru dan seluruh responden yang telah membantu sehingga penelitian ini bisa berjalan dan bisa diselesaikan dengan baik.

\section{DAFTAR PUSTAKA}

1. Asih Y, Risnaeni. Buku Ajar Asuhan Kebidanan Nifas dan Menyusui. Jakarta: Trans Info Media (TIM); 2016. 
2. Rukiyah Y, Yulianti L. Asuhan Kebidanan pada Ibu Masa Nifas bedasarkan Kurikulum Berbasis Kompetensi. Jakarta: Trans Info Media (TIM); 2018.

3. Nurafifah D, Kusbiantoro D. Effectiveness of Early Exercise Against Uterine Involution in Spontaneous Postpartum Patients. J Kesehat Masy [Internet]. 2019 Oct 6;15(1):1521. Available from: https://journal.unnes.ac.id/nju/index.php/kemas/article/view/11936

4. Sutanto AV. Buku Asuhan Kebidanan Nifas \& Menyusui Teori dalam Praktik Kebidanan Profesional. Yogyakarta: Pustaka Baru Press; 2018.

5. Kementerian Kesehatan R.I. Profil kesehatan Indonesia Tahun 2017. Jakarta: Kementerian Kesehatan R.I.; 2018.

6. Dinas Kesehatan Sulawesi Tengah. Profil Kesehatan Sulawei Tengah Tahun 2016. Palu; 2017.

7. Dinas Kesehatan Sulawesi Tengah. Profil Kesehatan Sulawei Tengah Tahun 2017. Palu: Dinas Kesehatan Sulawei Tengah; 2018.

8. Dinas Kesehatan Kabupaten Banggai. Profil Kesehatan Kabupaten Banggai Tahun 2017. Luwuk; 2018.

9. Dinas Kesehatan Kabupaten Banggai. Profil Kesehatan Kabupaten Banggai Tahun 2018. Luwuk; 2019.

10. Sugiyono. Metode Penelitian Kuantitatif Kualitatif dan R\&D. Jakarta: Alfabeta; 2017.

11. Kusparlina EP, Sundari S. Effectiveness of Early Exercise Against Uterine Involution in Spontaneous Postpartum Patients. Aloha Int J Heal Adv [Internet]. 2019 Oct 31;2(10). Available from: http://journal.aloha.academy/index.php/aijha/article/view/144

12. Susilowati D. Factors Affecting Mother Postpartum in the Implementation of Early Mobilization. J Infokes Apikes Citra Med. 2015;5(5):85-93.

13. Purwati Y. The Effect of Postpartum Exercise to Uterine Involution. SSRN Electron J. 2019;0966(2):38-42.

14. Ineke I. Pengaruh Senam Nifas terhadap Tinggi Fundus Uteri dan Jenis Lochea pada Primipara. J IIm Bidan. 2016;1(3):45-54.

15. Indriyastuti HI, Kusumastuti, Aryani T. Pengaruh Senam Nifas terhadap Kecepatan Involusi Uterus. Pengaruh Senam Nifas Terhadap Kecepatan. 2015;4(8):33-6.

16. Walyani ES, Purwoastuti E. Asuhan Kebidanan Masa Nifas dan Menyusui. Jakarta: Pustaka Baru Press; 2015. 